\title{
Determination of the Acid-Base Dissociation Constant of Acid- Degradable Hexamethylenetetramine by Capillary Zone Electrophoresis
}

\author{
Toshio Takayanagi, ${ }^{* \dagger}$ Natsumi Shimakami, $* *$ Masashi Kurashina, ${ }^{*}$ Hitoshi Mizuguchi, $*$ and \\ Tomoki YABUTANI*** \\ *Graduate School of Science and Technology, Tokushima University, 2-1 Minamijyousanjima-cho, \\ Tokushima 770-8506, Japan \\ **Graduate School of Advanced Technology and Science, Tokushima University, 2-1 Minamijyousanjima-cho, \\ Tokushima 770-8506, Japan \\ ***Paper Industry Innovation Center, Ehime University, 127 Mendori-cho, Shikokuchuo, Ehime 799-0113, \\ Japan
}

\begin{abstract}
The acid-base equilibrium of hexamethylenetetramine (hexamine) was analyzed with its effective electrophoretic mobility by capillary zone electrophoresis. Although hexamine is degradable in a weakly acidic aqueous solution, and the degraded products of ammonia and formaldehyde can be formed, the effective electrophoretic mobility of hexamine was measured in the $\mathrm{pH}$ range between 2.8 and 6.9. An acid-base dissociation equilibrium of the protonated hexamine was analyzed based on the mobility change, and an acid dissociation constant of $\mathrm{p} K_{\mathrm{a}}=4.93 \pm 0.01$ (mean \pm standard error, ionic strength: $0.020 \mathrm{~mol} \mathrm{dm}{ }^{-3}$ ) was determined. The monoprotic acid-base equilibrium of hexamine was confirmed through comparisons of its electrophoretic mobility with the $N$-ethylquinolinium ion and with the monocationic $N$-ethyl derivative of hexamine, as well as a slope analysis of the dissociation equilibrium.
\end{abstract}

Keywords Hexamethylenetetramine, acid-base equilibrium, capillary zone electrophoresis, acid degradation

(Received June 22, 2016; Accepted August 5, 2016; Published December 10, 2016)

\section{Introduction}

It is known that hexamethylenetetramine (hexamine, HMT) is degradable in an acidic solution and under heated conditions. ${ }^{1}$ Ammonia and formaldehyde are formed from hexamine by the degradation, as in reaction (1). ${ }^{1}$

$$
\mathrm{HMT}+6 \mathrm{H}_{2} \mathrm{O} \longrightarrow 4 \mathrm{NH}_{3}+6 \mathrm{HCHO}
$$

The degradation reaction of hexamine has been industrially utilized on phenolic resins, rubbers, and tires. ${ }^{1}$ On the other hand, the degradation of hexamine is sometimes troublesome. The release of waste water containing hexamine into river water induced formaldehyde contamination by a chlorination process at filtration plants of the Tonegawa water system in May, 2012. ${ }^{2}$ The decomposition reaction of hexamine was kinetically investigated in an acidic solution; ${ }^{3}$ hexamine degrades by hydrolysis from its protonated form, resulting in cleavage of the $\mathrm{C}-\mathrm{N}$ bond. ${ }^{3}$ Since hexamine is a base, the acid-base property of hexamine was investigated in an aqueous solution by potentiometric titration, and a $\mathrm{p} K_{\mathrm{a}}$ value of $4.89 \pm 0.03$ is reported for the mono-protonated hexamine. ${ }^{4} \mathrm{~A} \mathrm{p} K_{\mathrm{a}, 2}$ value of $-1.25 \pm 0.25$ has also been determined for diprotonated

† To whom correspondence should be addressed.

E-mail: toshio.takayanagi@ tokushima-u.ac.jp hexamine through the chemical shift in ${ }^{1} \mathrm{H}$ nuclear magnetic resonance in a more concentrated $\mathrm{DCl}$ and $\mathrm{D}_{2} \mathrm{O}$ solution; this leads a $\mathrm{p} K_{\mathrm{a}, 2}$ value of $-1.7 \pm 0.3$ for the diprotonated hexamine in light water. ${ }^{4}$ It is somewhat strange that the $\mathrm{p} K_{\mathrm{a}}$ value can be determined in a homogeneous solution by potentiometric titration, while one component of the equilibrium species of hexamine, the protonated one, is degradable in an acidic solution. This would be because the degradation is relatively slow (for protonated hexamine, first-order rate constant is $k_{\mathrm{w}}=6.05 \times 10^{-6} \mathrm{~s}^{-1}$, and the second-order rate constant with $\mathrm{H}^{+}$ is $\left.k_{\mathrm{h}}=6.33 \times 10^{-4} \mathrm{~s}^{-1} \mathrm{dm}^{3} \mathrm{~mol}^{-1}\right){ }^{3} \quad$ However, the kinetic reaction of the degradation would be excluded for a precise determination of the equilibrium constant, an acid dissociation constant, $\mathrm{p} K_{\mathrm{a}}$, in this case.

Capillary zone electrophoresis (CZE) is an alternative method for an analysis of the acid-base equilibrium in homogeneous solutions including conventional potentiometric and spectrophotometric titrations. In CZE, the equilibrium reactions are analyzed in an aqueous solution without any organic co-solvents and without any side reactions, such as a partition to the stationary phase. The acid-dissociation constants can be determined through measurements of the effective electrophoretic mobility of the equilibrium species of interest, and therefore other substances including impurities are allowed to coexist; they are resolved by CZE. ${ }^{5,6}$ In addition to the coexisting substances, gradually generated species are also resolved from the equilibrium species in fast equilibrium, and the fast 
equilibrium can be analyzed through the effective electrophoretic mobility of the equilibrium species. ${ }^{7,8}$ The acid-dissociation constants of alkaline-degradable phenolphthalein ${ }^{7}$ and alkalinelabile drug compounds ${ }^{8}$ were successfully determined by CZE in an aqueous solution. In addition to resolution of the degraded species from the equilibrium species, the equilibrium analysis by CZE is available and beneficial as much as the reaction equilibrium of interest is not affected by the formation kinetics of the degraded species. As for hexamine, a $\mathrm{p} K_{\mathrm{a}}$ value of 4.90 has also been determined by isotachophoresis with an effective electrophoretic mobility. ${ }^{9}$ However, the degraded species from hexamine are difficult to be resolved from the equilibrium species in the isotachophoresis.

In this study, the acid-base dissociation equilibrium of hexamine was investigated by CZE with measurements of the effective electrophoretic mobility of the equilibrium species. A monoprotic acid dissociation constant was determined with the monoprotonated hexamine. The monoprotic equilibrium was confirmed through the comparisons of its electrophoretic mobility with the $N$-ethylquinolinium ion and with monocationic $\mathrm{N}$-ethyl derivative of hexamine, as well as a slope analysis of the dissociation equilibrium.

\section{Experimental}

\section{Reagents and chemicals}

Hexamethylenetetramine was purchased from Kishida Chemical (Osaka, Japan). $N$-Ethylpyridinium chloride and $\mathrm{N}$-ethylquinolinium iodide were from Tokyo Chemical Industry (Tokyo, Japan). Tetramethylammonium hydroxide (TMAOH) was from Tama Chemicals (Kawasaki, Japan). A buffer component of 2-morpholinoethanesulfonic acid monohydrate (MES) was from Sigma-Aldrich (St. Louis, MO, USA). Other chemicals were of analytical grade. Water used was purified by a Milli-Q Gradient A10 (Merck-Millipore, Darmstadt, Germany).

$\mathrm{N}$-Ethyl derivative of hexamine was synthesized while referring to the synthesis of the $N$-methyl derivative. ${ }^{10}$ An aliquot of $1.00 \mathrm{~g}$ hexamine and an equivalent amount of ethyl iodide $(0.570 \mathrm{~mL})$ were dissolved in an aliquot of $50 \mathrm{~mL}$ of ethanol. The reaction solution was allowed to stand for $24 \mathrm{~h}$ at $40^{\circ} \mathrm{C}$. After the reaction, the precipitated needle-crystal was filtered and washed with ethanol. The product was analyzed by LC-MS.

\section{Apparatus}

An Agilent Technologies ${ }^{3 \mathrm{D}} \mathrm{CE}$ was used as a capillary electrophoresis system, equipped with a photometric diode array detector. A fused-silica capillary with an inner diameter of $50 \mu \mathrm{m}$ was purchased from GL Sciences (Tokyo, Japan). It was cut into a $64.5 \mathrm{~cm}$ length and was packed in a capillary cassette after making a detection window by burning the polyimide coating at the $8.5 \mathrm{~cm}$ point from one end of the capillary. The effective separation length was thus $56 \mathrm{~cm}$ from the injection point to the detection point. The capillary cassette was attached to the $\mathrm{CE}$ system and thermostated at $25^{\circ} \mathrm{C}$ by circulating temperature-controlled air. The capillary was refreshed every day by flushing it with $0.1 \mathrm{~mol} \mathrm{dm}^{-3} \mathrm{NaOH}$ for 2 min and with purified water for $3 \mathrm{~min}$. A capillary with an inner diameter of $75 \mu \mathrm{m}$ (GL Sciences) was also used for the indirect photometric detection and determination of hexamine and $\mathrm{NH}_{4}{ }^{+}$. The lengths of the capillary were also $64.5 \mathrm{~cm}$ in total length and $56 \mathrm{~cm}$ in effective separation length.

A Waters LCT Premire XE was used as an LC-MS system. A reversed-phase column of Acquity UPLC BEH C18 $(50 \mathrm{~mm}$ in length $\times 2.1 \mathrm{~mm}$ in inner diameter, particle size: $1.7 \mu \mathrm{m}$ ) was attached to the LC-MS system. A mixed solvent of $50 \%(\mathrm{v} / \mathrm{v})$ methanol in water was used as an eluent. An aliquot of $20 \mu \mathrm{L}$ of the sample solution was introduced into the LC-MS, and the MS detection was made by ESI-positive.

A TOA DKK (Tokyo, Japan) HM-25G pH meter equipped with a combined glass electrode was calibrated daily with the standard $\mathrm{pH}$ solutions; it was used for $\mathrm{pH}$ measurements of the separation buffers.

\section{Procedure for determining the acid-base dissociation constant of hexamethylenetetramine}

A series of the separation buffers were prepared with several buffer components with their ionic strength controlled at $0.020 \mathrm{~mol} \mathrm{dm}^{-3}$ by adding an appropriate amount of $\mathrm{NaCl}$ to it. The separation buffers used were: $0.020 \mathrm{~mol} \mathrm{dm}^{-3} \mathrm{H}_{3} \mathrm{PO}_{4}-\mathrm{NaOH}$ $\left(\mathrm{pH} 2.7\right.$ - 3.5), $0.020 \mathrm{~mol} \mathrm{dm}^{-3} \quad \mathrm{CH}_{3} \mathrm{COOH}-\mathrm{NaOH} \quad(\mathrm{pH} 4.0-$ 5.5 ), or $0.020 \mathrm{~mol} \mathrm{dm}^{-3} \mathrm{MES}-\mathrm{NaOH}(\mathrm{pH} 5.9-7.0$ ). After the capillary was filled with a separation buffer, a sample solution containing $5.0 \times 10^{-4} \mathrm{~mol} \mathrm{dm}^{-3}$ hexamine, $2.0 \times 10^{-5} \mathrm{~mol} \mathrm{dm}^{-3}$ $N$-ethylquinolinium as an internal standard, and $2.0 \%(\mathrm{v} / \mathrm{v})$ ethanol (EOF marker) was introduced into the capillary from its anodic end for $3 \mathrm{~s}$ by applying a pressure of $50 \mathrm{mbar}$ to the sample vial. Both ends of the capillary were dipped again to the separation buffer, and the electrophoresis was started by applying a $+15 \mathrm{kV}$ DC voltage. Hexamine was photometrically detected at $196 \mathrm{~nm}$. The effective electrophoretic mobility of hexamine, $\mu_{\mathrm{ep}, \mathrm{HMT}}{ }^{\prime}$, was calculated by the usual manner with the migration times of the electroosmotic flow (ethanol) and hexamine, as well as with the CZE conditions.

The degradation of hexamine was examined with $1.0 \times 10^{-2}$ mol dm ${ }^{-3}$ hexamine in an acidic aqueous solution with its $\mathrm{pH}$

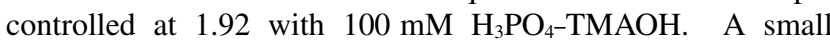
portion of the degradation solution was periodically sampled and diluted by 10 times with purified water. The diluted solutions were immediately subjected to indirect photometric determinations by CZE. The separation buffer contained $1.0 \times 10^{-3} \mathrm{~mol} \mathrm{dm}^{-3} \mathrm{~N}$-ethylpyridinium chloride as an indirect photometric reagent. A capillary of $75 \mu \mathrm{m}$ inner diameter was used in indirect photometric determinations. Both the residual hexamine and the formed ammonium ion were detected at $260 \mathrm{~nm}$ indirectly.

\section{Results and Discussion}

Degradation of hexamethylenetetramine at an acidic $p H$ region It is reported that hexamine is degradable under acidic $\mathrm{pH}$ conditions, and that ammonia and formaldehyde are generated by acid degradation. ${ }^{1-3}$ To examine the degradation profile of hexamine, the generated substances of ammonia and the residual hexamine were determined by CZE with indirect photometric detection. $N$-Ethylpyridinium chloride was used as an indirect photometric reagent with its concentration at $1.0 \times 10^{-3} \mathrm{~mol} \mathrm{dm}^{-3}$ in the separation buffer. The $\mathrm{pH}$ of the indirect CZE was controlled at 5.1 with buffer components of $20 \mathrm{mmol} \mathrm{dm}^{-3}$ MES-TMAOH. The analytes were indirectly detected at $260 \mathrm{~nm}$, and both the protonated hexamine and $\mathrm{NH}_{4}{ }^{+}$were detected as negative signals. Unfortunately, formaldehyde as one of the degradation product is neutral, and it still cannot be detected by indirect CZE. The calibration curves for $\mathrm{NH}_{4}{ }^{+}$and protonated hexamine were linear with their peak area in the concentration ranges between 0 to $1.0 \times 10^{-3} \mathrm{~mol} \mathrm{dm}^{-3}$ for hexamine (6 concentrations, $r=0.985)$ and 0 to $4.0 \times 10^{-3}$ mol dm${ }^{-3}$ for $\mathrm{NH}_{4}^{+}(9$ concentrations, $r=0.994)$. 

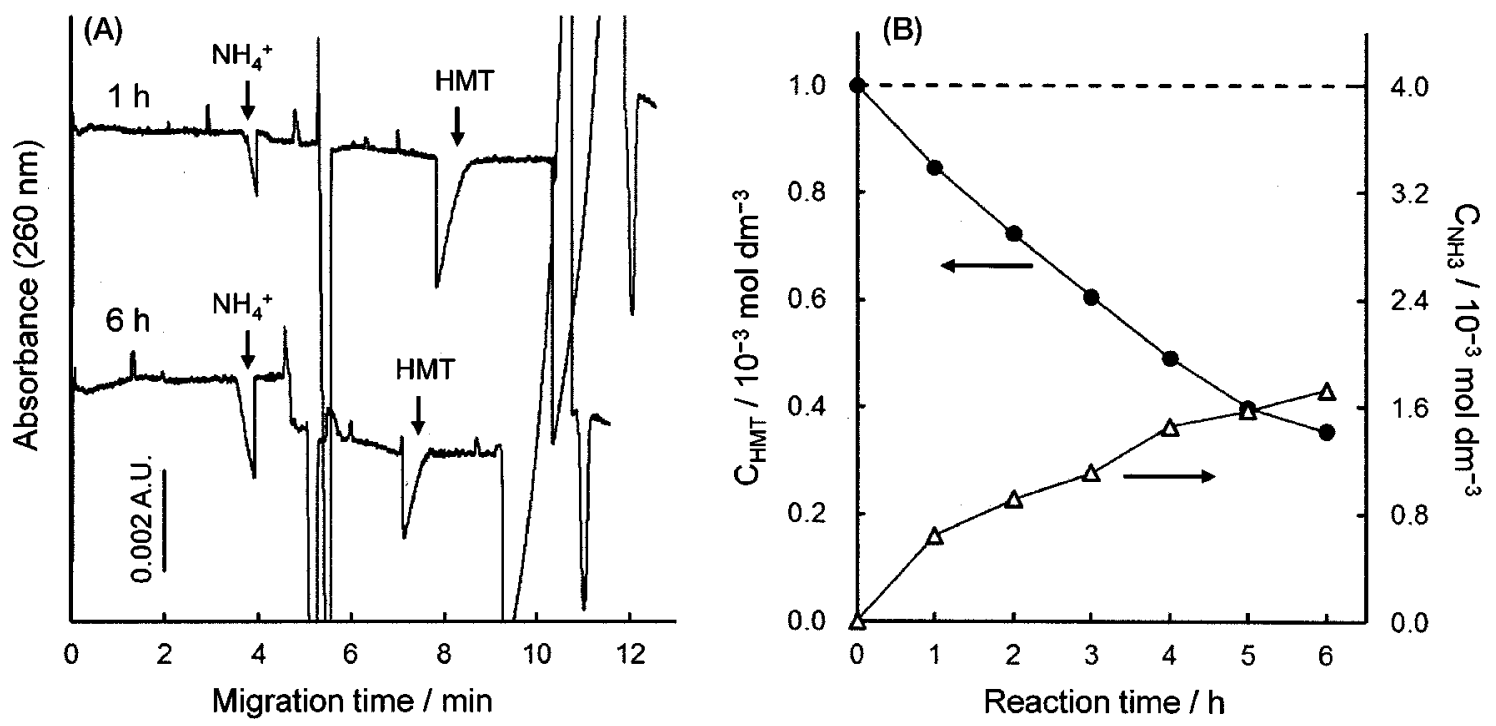

Fig. 1 Degradation monitoring of hexamine in an acidic aqueous solution. The degradation and the CZE conditions are written in the text. (A) Electropherograms for the degradation solution of hexamine measured by an indirect photometric CZE. Standing time: $1 \mathrm{~h}$ and $6 \mathrm{~h}$. Initial concentration of hexamine: $1.0 \times 10^{-2} \mathrm{~mol} \mathrm{dm}^{-3}$. (B) Degradation profile of hexamine with the reaction time. Residual hexamine and $\mathrm{NH}_{3}$ as a degradation product were determined by the indirect photometric CZE.

In a degradation study of the hexamine, it was dissolved in an acidic phosphate buffer solution with its $\mathrm{pH}$ controlled at 1.92 ; the solution was allowed to stand for several hours at $37^{\circ} \mathrm{C}$. A small portion of the hexamine solution was periodically sampled, and the sampled solution was diluted with the purified water by 10 times for the CZE analysis. Electropherograms of the degraded hexamine solution are shown in Fig. 1(A). The signals corresponding to the hexamine decreased with longer reaction time. On the contrary, the signals corresponding to $\mathrm{NH}_{4}{ }^{+}$increased with the reaction time. Quantification results on the residual hexamine and the generated $\mathrm{NH}_{4}{ }^{+}$are shown in Fig. 1(B). The residual concentration of hexamine decreased with the standing time by a first-order kinetic reaction. The conditional rate constant was calculated to be $k=4.9 \times 10^{-5} \mathrm{~s}^{-1}$ from the results. The conditional rate constant can also be calculated as $k=1.4 \times 10^{-5} \mathrm{~s}^{-1}$ with the reported parameters using $k=k_{\mathrm{w}}+k_{\mathrm{h}}\left[\mathrm{H}^{+}\right] .^{3} \quad$ Both of the conditional rate constants are comparable to each other in magnitude. On the other hand, the generation of $\mathrm{NH}_{4}{ }^{+}$was complementary to the decrease in hexamine; the amount of $\mathrm{NH}_{4}{ }^{+}$was approximately four-times that of the degraded hexamine. The stoichiometry agreed with the degradation reaction of hexamine, as in reaction (1).

Determination of acid-base dissociation constants through the effective electrophoretic mobility

The effective electrophoretic mobility of hexamine was measured with several separation buffers in the $\mathrm{pH}$ range between 2.8 and 6.9. Typical electropherograms are shown in Fig. 2. $N$-Ethylquinolinium ion was used as an internal standard of the electrophoretic mobility. The CZE signal of hexamine became closer to the EOF with increasing $\mathrm{pH}$ of the separation buffer. This result suggested that hexamine came to be neutral from acidic to neutral $\mathrm{pH}$ conditions. Changes in the effective electrophoretic mobility of hexamine were plotted against the $\mathrm{pH}$ of the separation buffer, as in Fig. 3, where the effective electrophoretic mobility of hexamine was standardized with that of the $N$-ethylquinolinium ion. The effective electrophoretic

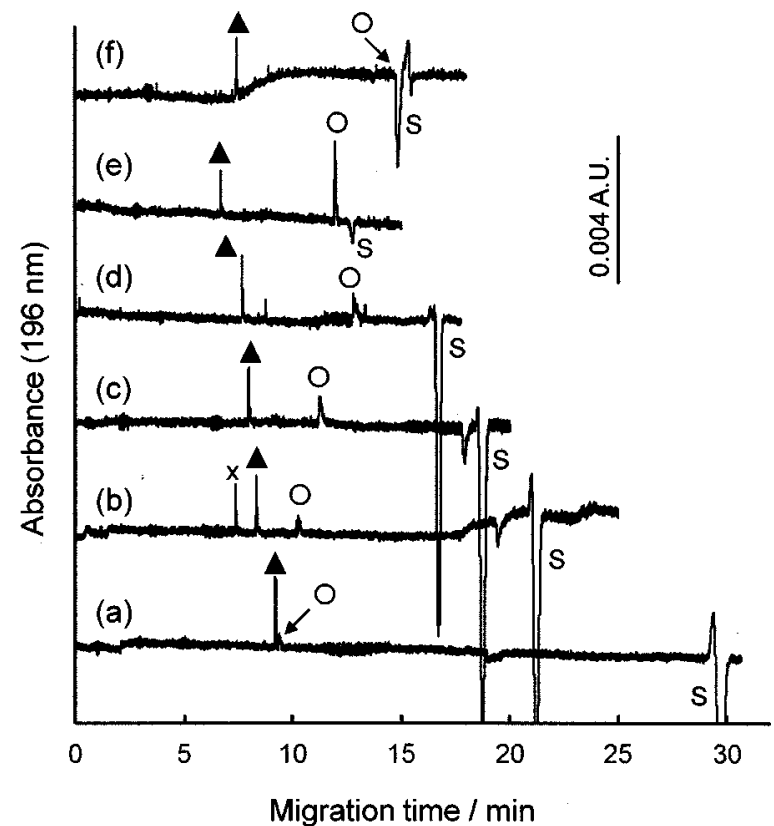

Fig. 2 Typical electropherograms for hexamine at several $\mathrm{pH}$ conditions. The CZE conditions are written in the text. $\mathrm{pH}$ conditions: (a) 4.02, (b) 4.69, (c) 5.01, (d) 5.46, (e) 5.93, (f) 6.91. Signals: $\bigcirc$, hexamine; $\boldsymbol{\Delta}, \mathrm{EtQu}^{+}$as a mobility standard. S, Solvent (EOF marker).

mobility of hexamine is positive in the acidic $\mathrm{pH}$ region and zero in the neutral $\mathrm{pH}$ region, as is expected from the electropherograms, as well as the acid-base equilibrium.

An acid dissociation constant of hexamine has been determined through the standardized electrophoretic mobility. Since hexamine possesses four tertiary amines, four steps of the protonation could be supposed. At this point, both one-step protonation and two-step protonation were assumed, as in the 


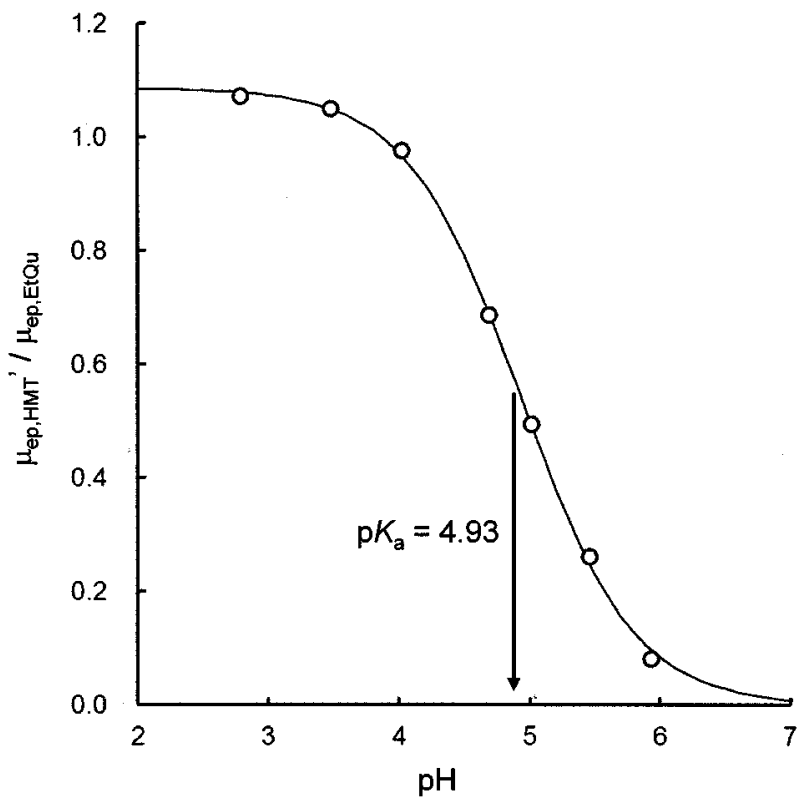

Fig. 3 Changes in the effective electrophoretic mobility of hexamine with varying $\mathrm{pH}$ of the separation buffer. The effective electrophoretic mobility of hexamine was standardized with the one of $\mathrm{EtQu}^{+}$, as $\mu_{\text {ep,HмT }} / \mu_{\text {ep,EtQu. }}$ The CZE conditions are written in the text.

following equilibria with the corresponding equilibrium constants. When one-step acid-dissociation equilibrium is associated with hexamine, an acid-dissociation equilibrium from monoprotonated hexamine, $\mathrm{HHMT}^{+}$, is written as follows with its acid dissociation constant, $K_{\mathrm{a}}$ :

$$
K_{\mathrm{a}}=\frac{\left[\mathrm{HMT}^{+}\left[\mathrm{H}^{+}\right]\right.}{\left[\mathrm{HHMT}^{+}\right]},
$$$$
\mathrm{HHMT}^{+} \rightleftharpoons \mathrm{HMT}+\mathrm{H}^{+}
$$

where $\mathrm{HHMT}^{+}$and HMT denote the protonated hexamine and hexamine, respectively. The effective electrophoretic mobility of hexamine, $\mu_{\mathrm{ep}, \mathrm{HMT}}{ }^{\prime}$, is contributed from the two species, and it is written as

$$
\mu_{\mathrm{ep}, \mathrm{HMT}}{ }^{\prime}=\frac{\left[\mathrm{H}^{+}\right] \mu_{\mathrm{ep}, \mathrm{HHMT}}+K_{\mathrm{a}} \mu_{\mathrm{ep}, \mathrm{HMT}}}{\left[\mathrm{H}^{+}\right]+K_{\mathrm{a}}} .
$$

The values of $\mu_{\text {ep,Hнмт }}$ and $\mu_{\text {ep,Hмт }}$ are the electrophoretic mobility of $\mathrm{HHMT}^{+}$and HMT, respectively. The deprotonated HMT is neutral, and the value of $\mu_{\mathrm{ep}, \mathrm{HMT}}$ can be set as zero in Eq. (4). A series of the pairs of $\left[\mathrm{H}^{+}\right]$and $\mu_{\mathrm{ep}, \mathrm{HMT}}{ }^{\prime}$ measured as in Fig. 3 were put in Eq. (4), and the values of $\mu_{\text {ep,ннмт and } K_{\text {a }}}$ were optimized by a non-linear least-squares analysis. ${ }^{11}$ The value of $\mu_{\mathrm{ep}, \mathrm{HMT}}{ }^{\prime}$ was standardized with the electrophoretic mobility of $\mathrm{EtQu}^{+}$, and the standardized value of $\mu_{\mathrm{ep}, \mathrm{HMT}}{ }^{\prime} / \mu_{\mathrm{ep}, \mathrm{EtQu}}$ was used for the analysis, since $\mathrm{EtQu}^{+}$is a monocation over a wide $\mathrm{pH}$ range, and its electrophoretic mobility is identical under the experimental conditions. Upon analyzing the $K_{\mathrm{a}}$ value, a software of $\mathrm{R}$ program (Ver. 3.1.1) was used. ${ }^{12} \mathrm{An}$ acid-dissociation constant of $\mathrm{p} K_{\mathrm{a}}=4.93 \pm 0.01$ (mean \pm standard error) was determined. The curve in Fig. 3 is drawn using the optimized results. Consequently, the $\mathrm{p} K_{\mathrm{a}}$ value determined in this study agrees well with those determined by potentiometry ${ }^{4}$ and isotachophoresis. ${ }^{9}$
On the other hand, when two steps of the acid-dissociation reactions are associated with a diprotonated hexamine, $\mathrm{H}_{2} \mathrm{HMT}^{2+}$, the acid-dissociation equilibria are written as in Eqs. (5) and (6), with the acid dissociation constants of $K_{\mathrm{a} 1}$ and $K_{\mathrm{a} 2}$, as in Eqs. (7) and (8):

$$
\begin{aligned}
& \mathrm{H}_{2} \mathrm{HMT}^{2+} \rightleftharpoons \mathrm{HHMT}^{+}+\mathrm{H}^{+}, \\
& \mathrm{HHMT}^{+} \rightleftharpoons \mathrm{HMT}+\mathrm{H}^{+}, \\
& K_{\mathrm{a} 1}=\frac{\left[\mathrm{HHMT}^{+}\right]\left[\mathrm{H}^{+}\right]}{\left[\mathrm{H}_{2} \mathrm{HMT}^{2+}\right]}, \\
& K_{\mathrm{a} 2}=\frac{\left[\mathrm{HMT}^{2+} \mathrm{H}^{+}\right]}{\left[\mathrm{HHMT}^{+}\right]},
\end{aligned}
$$

where $\mathrm{H}_{2} \mathrm{HMT}^{2+}$ denotes the diprotonated hexamine. In this case, the effective electrophoretic mobility of hexamine, $\mu_{\mathrm{ep}, \mathrm{HMT}}{ }^{\prime}$, is contributed from the three species of hexamine, and it is written as

$$
\mu_{\mathrm{ep}, \mathrm{HMT}}{ }^{\prime}=\frac{\left[\mathrm{H}^{+}\right]^{2} \mu_{\mathrm{ep}, \mathrm{H} 2 \mathrm{HMT}}+\left[\mathrm{H}^{+}\right] K_{\mathrm{a} 1} \mu_{\mathrm{ep}, \mathrm{HHMT}}+K_{\mathrm{a} 1} K_{\mathrm{a} 2} \mu_{\mathrm{ep}, \mathrm{HMT}}}{\left[\mathrm{H}^{+}\right]^{2}+\left[\mathrm{H}^{+}\right] K_{\mathrm{a} 1}+K_{\mathrm{a} 1} K_{\mathrm{a} 2}}
$$

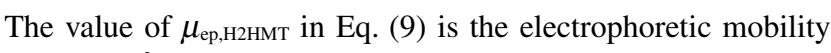
of $\mathrm{H}_{2} \mathrm{HMT}^{2+}$. The value of $\mu_{\mathrm{ep}, \mathrm{HHMT}}$ is set as one half of $\mu_{\mathrm{ep}, \mathrm{H} 2 \mathrm{HMT}}$, considering the charge of the hexamine species, and the value of $\mu_{\text {ep,HMT }}$ is also set to zero in Eq. (9). ${ }^{7}$ The data of the effective electrophoretic mobility in Fig. 3 were also put in Eq. (9), and the values of $K_{\mathrm{a} 1}, K_{\mathrm{a} 2}$ and $\mu_{\mathrm{ep}, \text { Н2нмт }}$ were optimized by a non-linear least-squares analysis, where the $\mathrm{R}$ program was also used. ${ }^{12}$ The values of $\mu_{\text {ep,HMT }}{ }^{\prime}$ were also standardized with the electrophoretic mobility of $\mathrm{EtQu}^{+}$. Acid-dissociation constants of $\mathrm{p} K_{\mathrm{a} 1}=4.64 \pm 0.04$ and $\mathrm{p} K_{\mathrm{a} 2}=5.23 \pm 0.03$ (mean \pm standard error) were determined. The acid-dissociation constants are close to each other, and the acid-dissociation reactions may proceed successively. A simulation curve with the optimized values also agreed with the experimental results.

\section{Confirming the monoprotic equilibrium through comparison of} the electrophoretic mobility

It is difficult to judge the acid-dissociation equilibrium if it is a one-step equilibrium or a more than one-step equilibria, only with the change in the electrophoretic mobility, as analyzed above. Since hexamine possesses four tertiary amines, it is uncertain how many protons may attach to hexamine in an aqueous solution. The number of the protonation to hexamine should be clarified in the acid-base equilibrium. The first approach was a direct comparison of the electrophoretic mobility. It is noted from Fig. 3 that the electrophoretic mobility of the protonated hexamine is almost comparable to that of $\mathrm{N}$-ethylquinolinium as an internal standard. The ratio of the electrophoretic mobility of the monoprotonated hexamine against $\mathrm{EtQu}^{+}$is about 1.08. The molecular weights of $\mathrm{EtQu}^{+}$ and monoprotonated hexamine are 158 and 141, respectively; they are close to with each other. The ratio of the molecular weight is almost inversely proportional to the electrophoretic mobility. Thus, the positively charged species of hexamine at an acidic $\mathrm{pH}$ of around $2-3$ would be the monoprotonated one.

Confirming the monoprotic equilibrium of hexamine through a slope analysis of the electrophoretic mobility

When the deprotonation reactions are successive, the aciddissociation reaction and its equilibrium constant from polyprotonated hexamine are written as in reaction (10) with its 
equilibrium constant (11). The number of the proton is indicated with " $n$ ".

$$
\begin{aligned}
& \mathrm{H}_{\mathrm{n}} \mathrm{HMT}^{\mathrm{n}+} \rightleftharpoons \mathrm{HMT}+n \mathrm{H}^{+}, \\
& K=\frac{[\mathrm{HMT}]\left[\mathrm{H}^{+}\right]^{\mathrm{n}}}{\left[\mathrm{H}_{\mathrm{n}} \mathrm{HMT}^{\mathrm{n}+}\right]} .
\end{aligned}
$$

Equation (11) can be converted into Eq. (12), using the electrophoretic mobility:

$$
\log \frac{[\mathrm{HMT}]}{\left[\mathrm{H}_{\mathrm{n}} \mathrm{HMT}^{\mathrm{n}+}\right]}=\log \frac{\mu_{\mathrm{ep}, \mathrm{HnHMT}}-\mu_{\mathrm{ep}, \mathrm{HMT}}{ }^{\prime}}{\mu_{\mathrm{ep}, \mathrm{HMT}}{ }^{\prime}}=\log K+n \mathrm{pH} .
$$

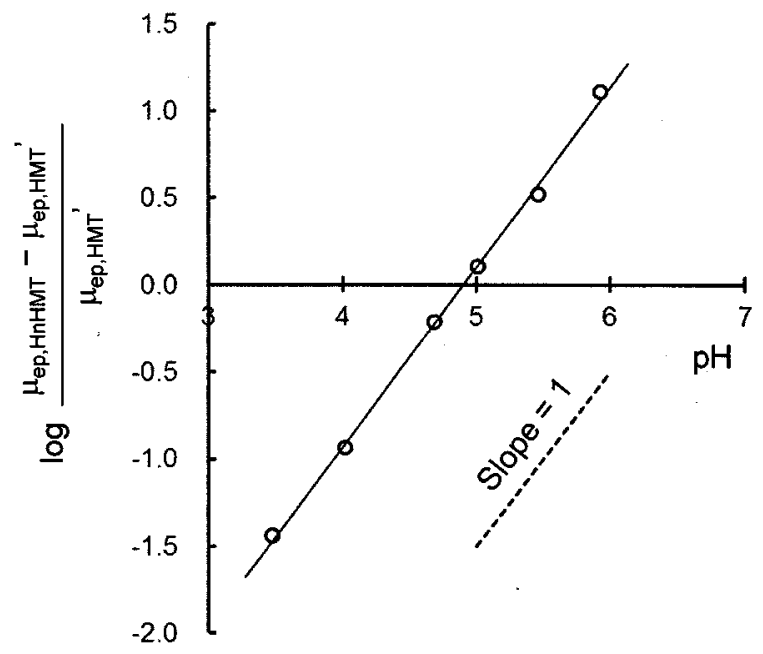

Fig. 4 Slope analysis of the equilibrium by log-log plots based on Eq. (12). The slope is 1.03 , which indicates that the equilibrium is monoprotic.
Data of the effective electrophoretic mobility of hexamine in Fig. 3 were plotted using Eq. (12). The result is shown in Fig. 4. A linear relationship is obtained with a slope of 1.03 . The slope, 1.03, indicates that the deprotonation reaction is one step ( $n=1$ in Eqs. (10) and (11)). This result also assures the monoprotic equilibrium of hexamine in this $\mathrm{pH}$ range. The $\mathrm{x}$-intercept of 4.90 corresponds to the $-\log K$ value in Eq. (12). It is close to the $\mathrm{p} K_{\mathrm{a}}$ value determined in Fig. 3 .

Confirming the monoprotic equilibrium of hexamine through the electrophoretic mobility of $\mathrm{N}$-ethylated hexamethylenetetramine

Another approach was made to confirm the number of the protonation of hexamine. Hexamine was derivatized to the $N$-ethylated one to possess a fixed +1 charge in a wide $\mathrm{pH}$ region. The $N$-ethylated hexamine $\left(\mathrm{HMT}^{\left.-\mathrm{Et}^{+}\right)}\right.$was synthesized as described in the experimental section, and a molecular mass of $169.1\left(\mathrm{M}^{+}\right)$was confirmed by LC-MS measurements. Electropherograms are shown in Fig. 5(A), where an indirect photometric detection of the cationic species was made with $1.0 \times 10^{-3} \mathrm{~mol} \mathrm{dm}^{-3} \mathrm{~N}$-ethylpyridunium chloride as an indirect photometric reagent. The migration time of $\mathrm{HMT}^{-\mathrm{Et}^{+}}$is obviously different from that of hexamine, as well as the electrophoretic mobility. The result suggests that the $N$-ethylated hexamine was successfully synthesized. The electrophoretic mobility of $\mathrm{HMT}^{-\mathrm{Et}^{+}}$was measured in the $\mathrm{pH}$ range between 4.8 and 9.7; the results are shown in Fig. 5(B). While the effective electrophoretic mobility of hexamine changes with $\mathrm{pH}$ by the acid-base equilibrium, $\mathrm{HMT}^{-} \mathrm{Et}^{+}$showed a positive electrophoretic mobility over a wide $\mathrm{pH}$ range. The positive electrophoretic mobility over the wide $\mathrm{pH}$ range also suggests that the $\mathrm{N}$-ethylated hexamine was successfully synthesized. The effective electrophoretic mobility of the protonated

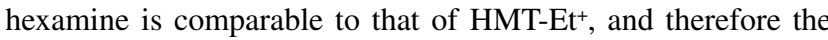
charge of the protonated hexamine would also be +1 .

The monoprotic equilibrium of hexamine was thus confirmed by the three approaches. A monoprortic $\mathrm{p} K_{\mathrm{a}}$ value of $4.93 \pm 0.01$ is attributed to hexamine.
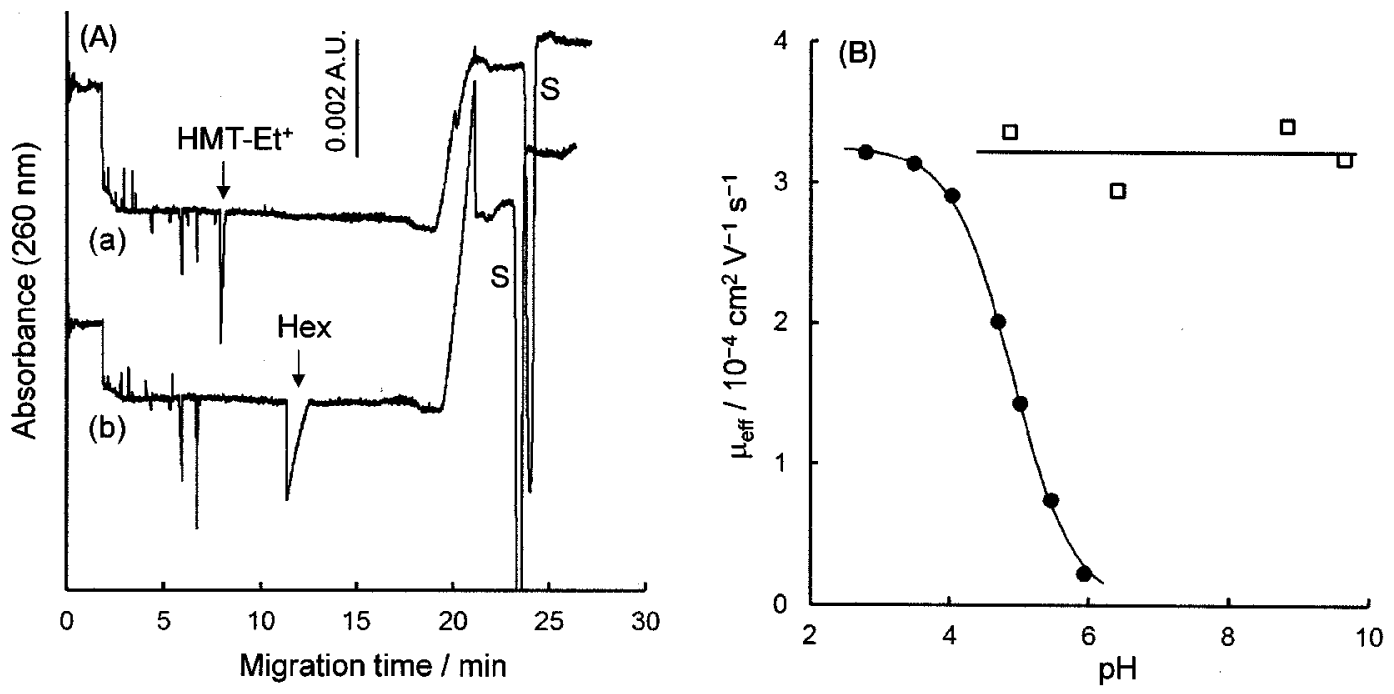

Fig. 5 Indirect photometric detection of HMT-Et ${ }^{+}$by CZE. (A) Electropherograms for (a), synthesized HMT-Et ${ }^{+}$at $5.0 \times 10^{-4} \mathrm{~mol} \mathrm{dm}^{-3}$; (b), hexamine at $5.0 \times 10^{-4} \mathrm{~mol} \mathrm{dm}^{-3}$. pH conditions of the separation buffer: 4.87. (B) Changes in the electrophoretic mobility of $\boldsymbol{\bullet}$, hexamine and $\square$, synthesized HMT-Et ${ }^{+}$. Conditions are written in the text. 


\section{Conclusions}

An acid-base dissociation constant of hexamethylenetetramine of protonated form was determined by CZE in an aqueous solution through measurements of the effective electrophoretic mobility under its dissociating $\mathrm{pH}$ range. One step of the acid dissociation equilibrium was confirmed with hexamine based on its electrophoretic mobility of the cationic species, slope analysis, as well as a comparison of its electrophoretic mobility with the $\mathrm{N}$-ethylated derivative. In this way, the equilibrium analysis by CZE has been demonstrated with hexamethylenetetramine by the resolution of the degraded species from the equilibrium species. Also, the formation kinetics of the degraded species is relatively slow against the acidbase equilibrium of hexamine; this analysis method is available and beneficial to such equilibria as the kinetic degradationreaction not affecting the reaction equilibrium of interest.

\section{Acknowledgements}

This study was supported in part by the Grant-in-Aid for Scientific Research Program (KAKENHI) of the Japan Society for the Promotion of Science (JSPS), Grant Number 26410154. The authors are grateful to Dr. Fujinaga (Tokushima University) and Dr. Ueta (Tokushima University) for the LC-MS measurements.

\section{References}

1. J. M. Dreyfors, S. B. Jones, and Y. Sayed, Am. Ind. Hyg. Assoc. J., 1989, 50, 579.

2. T. Kanami, S. Abe, K. Tsuchiya, Y. Kobayashi, H. Imai, Y. Koyama, Y. Yano, K. Funahora, R. Katsumata, S. Iwanaga, and R. Ono, J. Jpn. Water Works Assoc., 2012, 81, 28.

3. H. Tada, J. Am. Chem. Soc., 1960, 82, 255.

4. A. P. Cooney, M. R. Crampton, and P. Golding, J. Chem. Soc. Perkin Trans. II, 1986, 835.

5. S. K. Poole, S. Patel, K. Dehring, H. Workman, and C. F. Poole, J. Chromatogr. A, 2004, 1037, 445.

6. P. Nowak, M. Woźniakiewicz, and P. Kościelniak, J. Chromatogr. A, 2015, 1377, 1.

7. T. Takayanagi and S. Motomizu, Chem. Lett., 2001, 14.

8. E. Örnskov, A. Linusson, and S. Folestad, J. Pharm. Biomed. Anal., 2003, 33, 379.

9. V. Jokl, M. Polášek, and J. Pospíchalová, J. Chromatogr., 1987, 391, 427.

10. H.-G. Ang, W. Fraenk, K. Karaghiosoff, T. M. Klapötke, H Nöth, J. Sprott, M. Suter, M. Vogt, and M. Warchhold, Z. Anorg. Allg. Chem., 2002, 628, 2901.

11. T. Takayanagi, Bunseki Kagaku, 2015, 64, 105.

12. The R Project for Statistical Computing, http://www.r-project. org/. 